\title{
Working Together
}

LONG-TIME READERS of this publication have seen the editors write this introductory note under the heading "Quarterdeck." Despite many months at sea on a variety of research vessels, and 16 months of editing this magazine, until recently I had no idea what a "quarterdeck" actually was. I just thought it was an old-fashioned ship's term that made a nice title for a column in a magazine devoted to the oceans. Thanks to a quick bit of googling, I learned that, according to one definition, the quarterdeck was "reserved for officers, and only they could walk the quarterdeck" (http://ladywashington.org/glossary.html). The restricted space of the quarterdeck was also where "the captain issued his commands" (http://collections.ic.gc.ca/vessels/terms.htm).

Conceptually and physically, the space from which this magazine is edited is far removed from the quarterdeck. The Internet, together with universal text and graphics formats, has obliterated the barriers between officers and crew. The editor is no longer the captain standing on the quarterdeck, issuing commands or watching officers barking orders, but rather is part of the ship's scientific party mucking around in the data. Files can be opened and updated-comments inserted, edits reviewed, graphics altered, and tables formatted—by editor or contributor. Finalizing an Oceanography manuscript is a collaborative effort.

Even though the Internet has been a part of our lives for years now, I still get giddy thinking about the ease of worldwide communication. The authors of articles in this issue hail from all over the world-Australia, Bulgaria, Canada, France, Germany, Iran, Ireland, Japan, Norway, Portugal, Romania, Russia, South Africa, Spain, Sweden, Turkey, Ukraine, the United Kingdom, and the United States. Yet they communicated with breathtaking speed to finalize their articles, as they used high-speed networks to respond to editorial queries, submit graphics files, and review proofs. Comments came in from Internet cafes in Istanbul, from contributors who were traveling in Bulgaria or Norway, and even from a ship sailing in the Black Sea. It goes without saying that without the Internet, this issue of the magazine would still be unfinished.

Nor could this issue have been completed without the extraordinary efforts of the contributors. We are very grateful to Jim Murray, Pat Glibert, and Grant Pitcher for guest editing this issue of Oceanography. Jim, Pat, and Grant received less time than most guest editors to put together this issue, but their considerable energies helped us to complete it in time for the June International Ocean Research Conference (sponsored by TOS and UNESCO/IOC) in Paris. We would also like to thank the U.S. National Science Foundation for supporting this issue of the magazine.

One final note. At the time of this writing, the March issue of Oceanography containing the special section on "Women in Oceanography" is arriving at people's doorsteps. Already discussions are beginning about what sort of follow-on activities might be coordinated. As those activities take shape, we will do our best to keep you informed of any new developments.

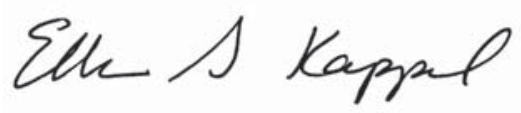

ELLEN S. KAPPEL, EDITOR 